Article

\title{
Deep Tunnel for Regulating Combined Sewer Overflow Pollution and Flood Disaster: A Case Study in Guangzhou City, China
}

\author{
Haichun Wu ${ }^{1}$, Guoru Huang ${ }^{2, *}$, Qingqiang Meng ${ }^{3}$, Mingzhu Zhang ${ }^{3}$ and Licheng Li $^{1}$ \\ 1 School of Civil Engineering and Transportation, South China University of Technology, Guangzhou 510640, \\ China; whcscut@163.com (H.W.); marclelee@foxmail.com (L.L.) \\ 2 State Key Laboratory of Subtropical Building Science, School of Civil Engineering and Transportation, \\ South China University of Technology, Guangzhou 510640, China \\ 3 Guangzhou City Water Science Research Institute, Guangzhou 510220, China; \\ sks2000@vip.163.com (Q.M.); gzsks@163.com (M.Z.) \\ * Correspondence: huanggr@scut.edu.cn; Tel.: +86-186-2016-8422
}

Academic Editor: Y. Jun Xu

Received: 2 June 2016; Accepted: 29 July 2016; Published: 5 August 2016

\begin{abstract}
The DongHaoChong (DHC) basin is located in the central city zone of Guangzhou City, China. Owing to the high density of buildings and low quality of the drainage pipe network in the city, diversion of rain and sewage is difficult. Waterlogging occurs frequently and combined sewer overflow (CSO) pollution is a serious problem during the rainy season. Therefore, a deep tunnel for the DongHaoChong basin has been planned and its construction is currently underway. An urban rainstorm model for the DongHaoChong basin was developed on the basis of the Storm Water Management Model (SWMM), and both the interception effect of CSO pollution and the degree of mitigation of flood were analyzed. Reasonable scenarios for the deep tunnel in terms of rainstorms with different design recurrence periods were evaluated. From the viewpoints of preventing rainstorm waterlogging disasters and protecting water quality in the region downstream of DongHaoChong River, the river flood control and drainage capacities of the region were improved to a 2-year rainstorm design recurrence period by the construction of the deep tunnel. Furthermore, the main pollutant load of the CSO is expected to be reduced by about $30 \%-40 \%$.
\end{abstract}

Keywords: combined sewer overflow pollution; deep tunnel engineering; DongHaoChong basin; flood disaster; SWMM model

\section{Introduction}

Guangzhou was once well known by the name of "water city" owing to its then-existing interlocking river network. Because of the hot and windless sub-tropical climate of Guangzhou, people prefer to live along rivers, close to the water. Therefore, activities such as eating, shopping, sightseeing, and traveling along and on the river are popular. However, with the rapid urbanization of Guangzhou, urban waterlogging, and combined sewer overflow (CSO) pollution have emerged as crucial problems because of the use of the combined sewer system in the older city zone [1,2]. Owing to these problems, the popularity of the region for recreation and travel has waned gradually over the past several decades. Meanwhile, rivers and riverfronts have degraded because of the polluted water, thereby resulting in unappealing and messy urban spaces. DongHaoChong River is an example of such an urban space [3]. However, since 2009, Guangzhou has made large financial investments for revitalizing the DongHaoChong region. To this end, a Clean DongHaoChong River Plan was introduced for reducing waterlogging disasters and CSO pollution. Among the measures taken as part of this plan, the final step was the construction of a deep tunnel drainage system. 
Deep tunnel drainage systems have been constructed in some developed countries to mitigate CSO pollution. The DongHaoChong deep tunnel is the first deep tunnel drainage system in China. The main aim of constructing this system was to reduce waterlogging disasters and CSO pollution. If the deep tunnels of DongHaoChong give remarkable results in the future, this technique may serve as an example from which other Chinese cities can learn. Therefore, it is important to study the construction of the deep tunnel drainage system of DongHaoChong as well as to evaluate it. In this paper, the current situation of the DongHaoChong basin and the regulation scenarios of the DongHaoChong deep tunnel are introduced. The urban rainstorm model of the DongHaoChong deep tunnel drainage system, built on the basis of the Storm Water Management Model (SWMM), is described. The SWMM was built with the aim of evaluating and optimizing the effectiveness of different regulation scenarios in order to provide a basis for the operation of the DongHaoChong deep tunnel drainage system.

\section{Materials and Methods}

\subsection{Present Situation of the Study Area}

With the development of industrial factories and residential areas along DongHaoChong River, the river water became severely polluted by sanitary sewage, and rainwater was discharged directly into the river without control. In addition, a viaduct that was built to solve Guangzhou's transportation problem covered the skyline of the river. At present, the flood control and drainage capacities of the DongHaoChong basin are such that it can withstand rainfall for a recurrence period of only one year.

DongHaoChong River, which is about $4.37 \mathrm{~km}(2.72 \mathrm{mi})$ long, is located in Yuexiu District of Guangzhou City. It originates from Lu Lake in the north and ends at Pearl River in the south. Moreover, it has been divided into northern and southern sections by the sewage interception sluice gate of DongHaoChong (SISGD). The northern section (from Lu Lake to Dongfeng Road) has a rectangular cross section that is about $2.36 \mathrm{~km}(1.47 \mathrm{mi})$ long and 5-8 m (16.4-26.25 ft) wide, and this section is covered. Since rain and sewage diversion or other sewage interception projects have not been implemented for this area, sanitary sewage constantly flows into this section directly. The southern section, which extends from Dongfeng Road up to the end, is about $2.01 \mathrm{~km}(1.25 \mathrm{mi})$ long and 8-32 $\mathrm{m}$ (26.25-105 ft) wide and is open. Moreover, because sewage interception projects have been implemented in this section, it contains clean water from the water treatment plant (WTP). The WTP processes raw water pumped from Pearl River by using the make-up water pumping station. Hence, the water quality and the landscape of the riverfront of this section are much better than those of the northern section. Furthermore, interception boxes are placed on both sides of the southern section to capture the sewage and divert it to a wastewater treatment plant (WWTP). The SISGD intercepts the sewage from upstream and diverts it into the west-side interception box along the river. However, owing to the limited floodwater transportation capacity of the west-side interception box, the SISGD must be open in order to drain floodwater in the event of a rainstorm in the basin. In such an event, combined sewage and a large quantity of silt from the upstream of DongHaoChong River flow into the downstream of the river, thereby affecting the downstream water quality significantly. Additionally, Xinhepu, which is about $2.18 \mathrm{~km}$ long and $11 \mathrm{~m}$ wide, flows into DongHaoChong River from east to west at a distance of about $520 \mathrm{~m}(0.323 \mathrm{mi})$ from the downstream outlet.

In the DongHaoChong basin, a flood drainage sluice gate of Lu Lake (FDSGLL), a WTP, a Xinhepu-Dongshan Lake sluice gate (XHP-DSHLSG), a tidal sluice gate of DongHaoChong (TSGD), the Jiangwan pumping station (JWPS), and other similar structures were constructed (Figure 1). 


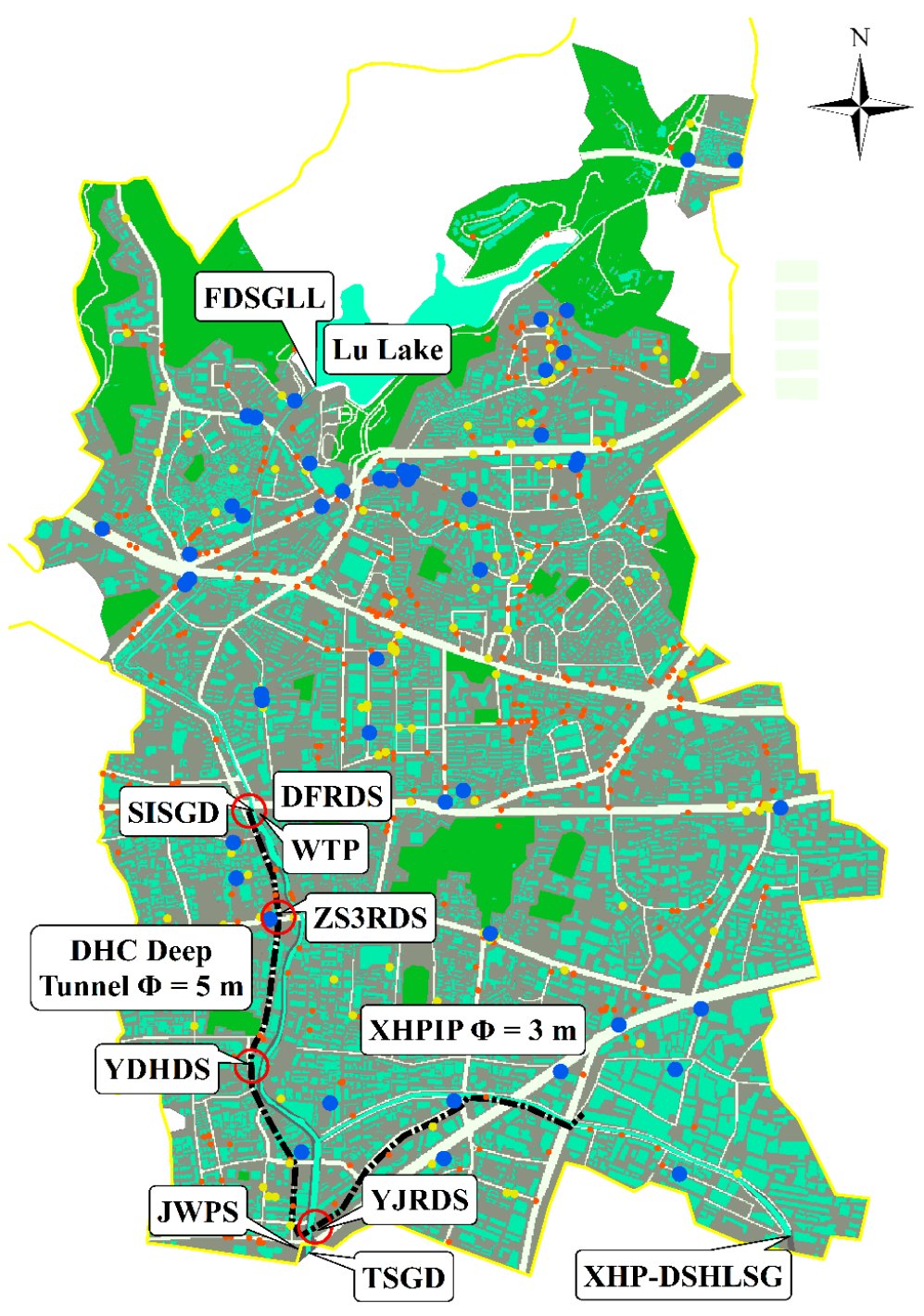

Figure 1. Basic survey map of the DongHaoChong basin.

\subsection{DongHaoChong Deep Tunnel}

With the aim of solving the problems of flood and deterioration of water quality of the DongHaoChong basin, a deep tunnel was planned and designed that would provide temporary storage for stormwater and sewage that cannot be drained in time by the west-side interception box, thereby ensuring the quality of the water and reducing peak flows downstream [4]. In the rainstorm event, the tunnel can also be used to transport floodwater and mitigate the pressure of the DongHaoChong flood drainage, so as to reduce the occurrence of waterlogging disasters in the DongHaoChong basin. The design can safeguard the water quality downstream and solve the problems related to flood and waterlogging upstream [5].

The DongHaoChong deep tunnel will start at the intersection of Dongfeng Road and the western part of the bottom of the DongHaoChong viaduct. The deep tunnel will terminate at the JWPS near Pearl River, running north to south along DongHaoChong River. The inner diameter of the deep tunnel is designed to be $5 \mathrm{~m}(16.4 \mathrm{ft})$, and it will be about $1.77 \mathrm{~km}(1.1 \mathrm{mi})$ long and $32-36 \mathrm{~m}(105-118 \mathrm{ft})$ deep. Further, the construction of a total of four drop shafts, the Dongfeng Road drop shaft (DFRDS), Zhongshan 3 Road drop shaft (ZS3RDS), Yudaihao drop shaft (YDHDS), and Yanjiang Road drop shaft (YJRDS), along the deep tunnel is also planned. These drop shafts will be interconnected with the deep tunnel and will be used to transport sewage from the tributary areas. Additionally, these drop shafts 
are designed for diverting the sewage to the deep tunnel, for serving as tunnel venting, for providing energy dissipation, and for flow control [6-9]. A drop shaft is a structure composed of two different components that are implemented throughout the system: a large drop shaft and a small air shaft (Figure 2). Of these two components, the large drop shaft is used for large inflows; it is separate from the small airshaft, which is used for venting and which is constructed immediately adjacent to the large drop shaft. This small air shaft typically terminates several feet below the ground level and is connected to the large drop shaft by a crossover pipe above the elevation of the connecting sewer network [10]. The DFRDS, ZS3RDS, YDHDS, and YJRDS are located at distances of $1.77 \mathrm{~km}(1.1 \mathrm{mi}), 1.4 \mathrm{~km}(0.87 \mathrm{mi})$, $0.9 \mathrm{~km}(0.56 \mathrm{mi})$, and $0.1 \mathrm{~km}(0.06 \mathrm{mi})$, respectively, from the JWPS. The maximum designed flows entering the DFRDS, ZS3RDS, YDHDS, and YJRDS are $31 \mathrm{~m}^{3} / \mathrm{s}$ (707 MGD (million gallons per day)), $4.8 \mathrm{~m}^{3} / \mathrm{s}$ (109 MGD), $4.8 \mathrm{~m}^{3} / \mathrm{s}$ (109 MGD), and $23 \mathrm{~m}^{3} / \mathrm{s}$ (524 MGD), respectively. The total storage space of the DongHaoChong deep tunnel is about 63,000 $\mathrm{m}^{3}$ (16.64 MG (million gallons)). The storage space of the main tunnel is about $34,700 \mathrm{~m}^{3}$ (9.17 MG), and that of the Xinhepu interception pipes (XHPIP) is about $9900 \mathrm{~m}^{3}$ (2.62 MG). The storage space of the drop shafts and their connecting parts to the deep tunnel is about $18,400 \mathrm{~m}^{3}$ (4.86 MG). The JWPS is composed of a flood drainage pump unit, sewage drainage pump unit, and landscape make-up water pump unit; the maximum flow rates of these components are $48 \mathrm{~m}^{3} / \mathrm{s}$ (1094 MGD), $0.89 \mathrm{~m}^{3} / \mathrm{s}$ (20.3 MGD), and $1.65 \mathrm{~m}^{3} / \mathrm{s}$ (37.6 MGD), respectively.

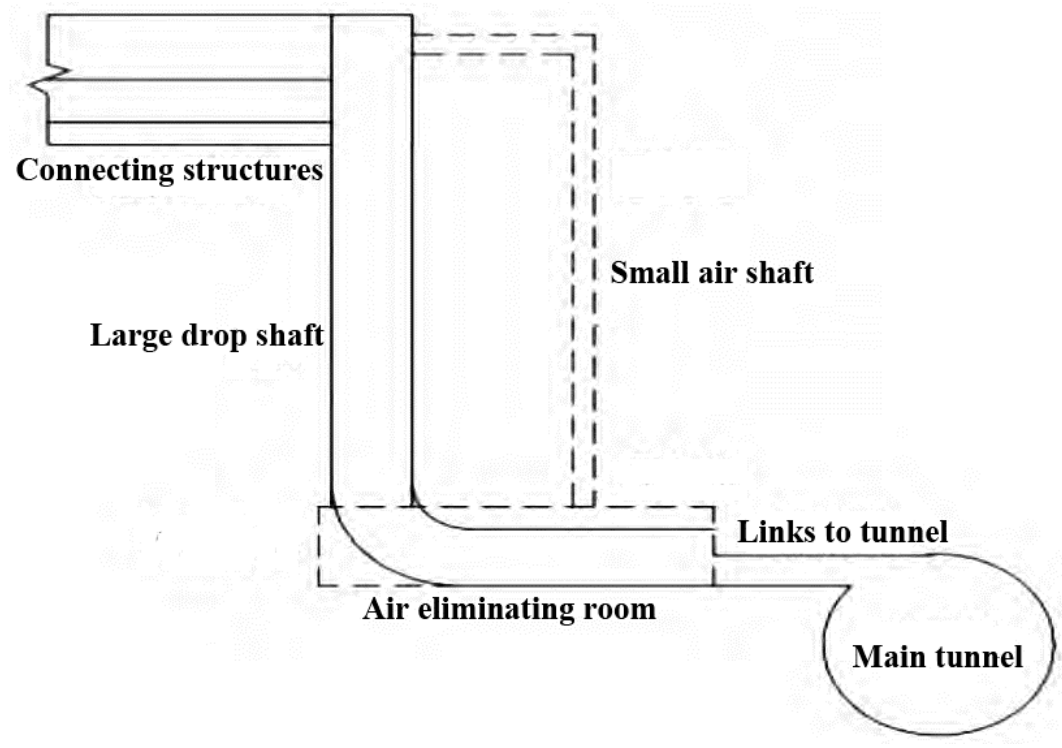

Figure 2. Schematic of drop shaft.

\subsection{Development of the SWMM Model of DongHaoChong Basin}

The US Environmental Protection Agency's SWMM 5.1 is a comprehensive mathematical model. It can be used to simulate an integrated urban rainfall runoff and pollutant transportation process, including the generation and transport of surface runoff flows, and the hydraulics and transportation of water and the water quality in a drainage system [11,12]. The flow and water quality in the study area can be determined from the SWMM simulation results. Additionally, this model can simulate not only a single rainfall event dynamically but also the runoff generated by continuous rainfall, the water quantity, and water quality changes after importing the drainage network system [13]. Basic data for DongHaoChong District, such as its topographic maps, satellite images, drainage network diagrams, and land use types, were used to build the DongHaoChong urban rainstorm model [14]. The key steps of development of the urban rainstorm model are as follows. 


\subsubsection{Generalization of the Drainage Pipe Network System}

Owing to the complexity of the underground pipe network, it is necessary to neglect some of the pipes, e.g., those that are of a shorter length or located at the start of the pipeline, in the generalization of the drainage pipe network system. Furthermore, the river should be considered the primary portion of the drainage pipe network system because this system drains the sewage into the end portion of DongHaoChong River. In the generalization, these rivers are generalized as conduits with different parameters on the basis of the length and width of the river. Moreover, the river conduits end at an outlet when the DongHaoChong River arrives at Pearl River. Given that even a street can be used to transport floodwater, streets are also generalized as conduits with a height of $0.15 \mathrm{~m}$ and a width depending on the street in question [15].

After drawing the conduits according to the drainage pipe network diagrams, it was important to analyze the drainage network flow according to the terrain. The DongHaoChong basin was generalized as 8425 pipes and 7702 nodes. Thereafter, the deep tunnel was generalized as a pipe with an inner diameter of $5 \mathrm{~m}$ and depth of 32-36 m below the ground that ended at an outlet. Additionally, the drop shafts were generalized as orifices especially given the flow control and energy dissipation function of the drop shafts. What is more, the drop shafts and the orifices had the same the discharge flow equation (Equation (1)) $[7,16,17]$. The sluice gate switches were controlled via controlling rules. Finally, the drainage pumping stations and regulation rules presented in the subsequent sections were merged with the SWMM model. The drop shafts and the orifices discharge flow equation is

$$
Q=C A \sqrt{2 g h}
$$

where $Q$ is flow rate, $C$ is discharge coefficient, $A$ is area of orifice opening, $g$ is acceleration of gravity, and $h$ is head difference across the orifice.

\subsubsection{Division of the Catchment Area}

On the basis of the distribution map of the basin's digital elevation model (DEM), streets, roads, and 11 sub-basin areas of the DongHaoChong basin were divided using ArcGIS. After division, adjustment, and merging, the basin was divided into 77 catchments according to streets, pipes, and buildings. Then, these sub-catchments were divided further. Given the fact that the topography of the basin is extremely flat for the most part, more attention was paid to the distribution of streets and community units in the division process. The DongHaoChong basin was divided into 7702 sub-catchments by the use of Thiessen polygons. The outlet of each sub-catchment was also designated. The outlet was either a node of the drainage network or the sub-catchment of the downstream sub-basin [18].

The value of the slope is one of the sensitive parameters of the sub-catchment. The average slope of the sub-catchment of the DongHaoChong basin was calculated using the ArcGIS raster surface slope tool on the DongHaoChong DEM [19]. All types of land use information (e.g., land for roads and squares, roofs, urban green belts, and parks) were extracted from a topographic map and Google Maps; this information was used to determine the imperviousness of all sub-catchments.

\subsubsection{Setting of the Model Parameters}

The model parameters can be divided into two categories: "measurement parameters", which can be obtained from measurements, and "calibration parameters", which need to be optimized [20]. The measurement parameters include the area of the sub-catchment, imperviousness (calculated from the land use type), average slope, bottom elevation and depth of nodes, and length and slope of the pipeline. The calibration parameters include the Manning coefficients of the pervious and impervious sub-catchments, the depth of depression storage, and the Manning coefficient of the pipe $[16,17]$. In view of the relevant information, these parameters were given the initial estimates or starting values. After calibrating, the final specific parameters of the model are as follows for infiltration by the Horton 
mode: maximum rate on the Horton infiltration curve is $87.1 \mathrm{~mm} / \mathrm{h}$, minimum rate on the Horton infiltration curve is $3.3 \mathrm{~mm} / \mathrm{h}$, depth of the depression storage in the impervious area, is $2.5 \mathrm{~mm}$, depth of the depression storage in the pervious area is $5.0 \mathrm{~mm}$, percent of the impervious area with no depression storage is $25 \%$, manning's $\mathrm{N}$ for the impervious area is 0.011 , manning's $\mathrm{N}$ for the pervious area is 0.024 , and decay constant for the Horton infiltration curve is 3.35. Meanwhile, the pollutant build-up and wash-off processes can be best replicated using a Saturation equation and an exponential equation, respectively, based on the rainwater quality measured. The calibrated relevant parameters of the pollutant build-up and wash-off processes are as follows (Table 1).

Table 1. The model parameters of pollutant build-up and wash-off processes.

\begin{tabular}{cccccccc}
\hline Land Surfaces & Parameters & TSS & BOD & COD & TP & TN & NH $-\mathbf{N}$ \\
\hline \multirow{5}{*}{ The roof } & Washoff Coefficient & 0.008 & 0.002 & 0.005 & 0.015 & 0.004 & 0.004 \\
& Washoff Exponent & 1.8 & 1.7 & 1.7 & 1.8 & 1.5 & 1.5 \\
& Cleaning Efficiency (\%) & 70 & 70 & 70 & 70 & 70 & 70 \\
& Max. Buildup (kg/ha) & 180 & 10 & 60 & 0.3 & 7.5 & 2 \\
& Power/Sat. Constant (d) & 7 & 7 & 7 & 7 & 7 & 7 \\
\hline \multirow{5}{*}{ The road } & Washoff Coefficient & 0.008 & 0.003 & 0.008 & 0.008 & 0.002 & 0.002 \\
& Washoff Exponent & 1.8 & 1.7 & 1.8 & 1.6 & 1.4 & 1.5 \\
& Cleaning Efficiency (\%) & 70 & 70 & 70 & 70 & 70 & 70 \\
& Max. Buildup (kg/ha) & 230 & 16 & 110 & 0.2 & 5 & 2 \\
& Power/Sat. Constant (d) & 4 & 4 & 4 & 4 & 4 & 4 \\
\hline \multirow{5}{*}{ The grass } & Washoff Coefficient & 0.03 & 0.008 & 0.03 & 0.042 & 0.007 & 0.008 \\
& Washoff Exponent & 1.2 & 1.2 & 1.2 & 1.2 & 1.2 & 1.2 \\
& Cleaning Efficiency (\%) & 0 & 0 & 0 & 0 & 0 & 0 \\
& Max. Buildup (kg/ha) & 100 & 20 & 40 & 1 & 10 & 1.8 \\
& Power/Sat. Constant (d) & 20 & 20 & 20 & 20 & 20 & 20 \\
\hline
\end{tabular}

\subsubsection{Setting of the Rainfall Simulation}

In the design rainfall graph for different rainstorm design recurrence periods, rainfall was calculated according to the formula of storm intensity for Guangzhou City, which was obtained using the annual multi sample method based on the storm rainfall data of the last 30 years [21].

$$
q=\frac{3618.427(1+0.438 \operatorname{Lg} P)}{(t+11.259)^{0.75}}
$$

Here, $q$ is the design storm intensity (L/s.ha), $t$ is the rainfall duration ( $\mathrm{min})$, and $P$ is the design return period (year).

The type of rainfall pattern chosen was the Chicago rainfall pattern.

$$
\begin{cases}0 \leqslant t \leqslant t_{a} & i_{a}=\frac{(1-n) r^{n} A(1+C \lg P)}{\left(t_{a}-t+r b\right)^{n}}+\frac{n b r^{n+1} A(1+C \lg P)}{\left(t_{a}-t+r b\right)^{n+1}} \\ t_{a} \leqslant t \leqslant t_{a}+t_{b} & i_{b}=\frac{(1-n)(1-r)^{n} A(1+C \lg P)}{\left[t-t_{a}+(1-r) b\right]^{n}}+\frac{n b(1-r)^{n+1} A(1+C \lg P)}{\left[t-t_{a}+(1-r) b\right]^{n+1}}\end{cases}
$$

Here, $A, n, b, C$, and $P$ are the parameters for the Guangzhou City formula of storm intensity, which are taken from Equation (2); specifically, $A=3618.427, n=0.75, b=11.259, C=0.438$, and $P$ is the design return period. Further, $i_{a}$ is the instantaneous rainfall intensity before the peak $(\mathrm{mm} / \mathrm{min}), i_{b}$ is the instantaneous rainfall intensity after the peak $(\mathrm{mm} / \mathrm{min}), t_{a}$ is the duration before the peak ( $\left.\mathrm{min}\right)$, $t_{b}$ is the duration after the peak ( $\mathrm{min}$ ), and $r$ is the relative position of the peak of the rainfall.

Most international data indicate that most of the $r$ values lie between 0.3 and 0.5 . In the present study, $r$ was taken as 0.4 . Further, the rainfall duration was suggested to employ $5 \mathrm{~min}, 10 \mathrm{~min}, 15 \mathrm{~min}$, $20 \mathrm{~min}, 30 \mathrm{~min}, 45 \mathrm{~min}, 60 \mathrm{~min}, 90 \mathrm{~min}$, or $120 \mathrm{~min}$, and it was taken as $60 \mathrm{~min}$ since the durations of rainstorm events are mostly around $1 \mathrm{~h}$ (i.e., $60 \mathrm{~min}$ ) in Guangzhou City [21]. 


\subsection{Model Calibration and Validation}

In order to ensure the reasonableness of the model, it is necessary to compare the calculated water quality with the actual water quality. The calibration methods can be divided into two categories: manual calibration and automatic calibration [22,23]. Although manual calibration is considered time consuming and labor intensive in comparison to automatic calibration, manual calibration is still predominant in China. A manual calibration technique has been used in this study, which is based on the trial calculation method. Since the entire DongHaoChong basin and the calibration parameters can also be transposed from those for a similar hydrometeorological region, the Xinhepu region in DongHaoChong basin was considered as an example, and a typical part of the drainage area was selected to monitor rainwater quality [16,17]. The average, minimum, and maximum rainwater quality measured are presented in Table 2. Further, a Xinhepu urban rainstorm model was built using the same parameters as those of the DongHaoChong urban rainstorm model based on the SWMM. Xinhepu, which is located in the southeastern part of the DongHaoChong basin, has rainfall runoff characteristics, pollution sources, and land use types similar to those of the present study area. The SWMM model was calibrated by comparing the actual maximum measured with the calculated maximum using the corresponding precipitation data obtained from rain gauges, of which the calibration and validation results are presented in Table 2. The results demonstrate that the model has good precision and reliability.

Table 2. Comparison of actual and calculated water qualities for model calibration.

\begin{tabular}{cccccccc}
\hline $\begin{array}{c}\text { Land Surface } \\
\text { (Date of } \\
\text { Rainfall Event) }\end{array}$ & $\begin{array}{c}\text { Concentration of } \\
\text { Pollutant }\end{array}$ & $\begin{array}{c}\text { TSS } \\
(\mathbf{m g} / \mathbf{L})\end{array}$ & $\begin{array}{c}\text { BOD } \\
(\mathbf{m g} / \mathbf{L})\end{array}$ & $\begin{array}{c}\text { COD } \\
(\mathbf{m g} / \mathbf{L})\end{array}$ & $\begin{array}{c}\text { TP } \\
(\mathbf{m g} / \mathbf{L})\end{array}$ & $\begin{array}{c}\text { TN } \\
(\mathbf{m g} / \mathbf{L})\end{array}$ & $\begin{array}{c}\mathbf{N H}_{\mathbf{4}}-\mathbf{N} \\
(\mathbf{m g} / \mathbf{L})\end{array}$ \\
\hline & Average value & 134.61 & 2.34 & 30.92 & 0.47 & 1.02 & 0.20 \\
Roof & Minimum & 54.00 & 0.00 & 16.40 & 0.17 & 0.39 & 0.01 \\
$(08 / 17 / 2010)$ & Actual maximum & 318.50 & 3.55 & 44.40 & 1.10 & 2.92 & 0.94 \\
& Calculated maximum & 324.86 & 3.82 & 53.20 & 0.94 & 3.04 & 0.81 \\
& Error of maximum (\%) & 2.00 & 7.61 & 19.82 & -14.55 & 4.11 & -13.83 \\
\hline & Average value & 236.13 & 7.26 & 193.31 & 0.15 & 0.95 & 0.47 \\
Road & Minimum & 51.50 & 3.90 & 143.44 & 0.07 & 0.83 & 0.35 \\
$(07 / 22 / 2010)$ & Actual maximum & 596.00 & 13.50 & 241.81 & 0.32 & 1.14 & 0.64 \\
& Calculated maximum & 622.61 & 13.41 & 263.50 & 0.31 & 1.15 & 0.62 \\
& Error of maximum (\%) & 4.46 & -0.67 & 8.97 & -3.13 & 0.88 & -3.13 \\
\hline & Average value & 114.50 & 5.81 & 48.00 & 1.89 & 2.31 & 0.33 \\
Grass & Minimum & 51.50 & 3.90 & 23.73 & 1.64 & 1.50 & 0.19 \\
$(08 / 17 / 2010)$ & Actual maximum & 168.50 & 7.35 & 62.40 & 2.15 & 3.27 & 0.67 \\
& Calculated maximum & 152.66 & 8.20 & 61.07 & 2.13 & 3.59 & 0.74 \\
& Error of maximum (\%) & -9.40 & 11.56 & -2.13 & -0.93 & 9.79 & 10.45 \\
\hline
\end{tabular}

\section{Results and Discussion}

Different regulation scenarios with different rainstorm design recurrence periods for deep tunnel engineering in the event of a rainstorm in the DongHaoChong basin were evaluated in this study. Further, the interception effect of CSO pollution and the degree of mitigation of flood were analyzed using the built DongHaoChong urban rainstorm model, and the comprehensive efficiency of deep tunnel engineering was evaluated quantitatively.

\subsection{Regulation Rule of Deep Tunnel Drainage System}

When the shallow drainage system exceeds its drainage capacity and overflows during rainfall events of different intensities, the drop shaft sluice gates are opened to provide storage space for the shallow drainage system. However, the SISGD remains shut until this time. Additionally, the sewage drainage pump unit is opened in order to transport the sewage to the WWTP, allowing the creation 
of extra storage space for the deep tunnel drainage system. Until the rainfall stops, the SISGD, flood drainage pump unit, and the four drop shaft sluice gates are shut off if they were not already closed. After transportation of all the sewage to the WWTP, the deep tunnel is cleaned and the sewage drainage pump unit is closed.

The regulation rules of the deep tunnel drainage system are categorized mainly as light rain, moderate rain, and heavy rain. Three scenarios based on whether a particular step was performed are considered, as presented in Table 3. (In the table, the symbol $x$ indicates that a step was not performed in a scenario, whereas the symbol $\sqrt{ }$ indicates that a step was performed.).

Table 3. Steps I and II in different scenarios.

\begin{tabular}{cccc}
\hline Scenario & Light Rain & Moderate Rain & Heavy Rain \\
\hline Step I & $\mathrm{x}$ & $\sqrt{ }$ & $\sqrt{ }$ \\
Step II & $\mathrm{x}$ & $\mathrm{x}$ & $\sqrt{ }$ \\
\hline
\end{tabular}

Step I: When the water quality of the upstream SISGD meets the requirements, the SISGD is opened to discharge floodwater. The drop shaft sluice gates along the deep tunnel drainage system are shut off. This step does not affect the downstream water quality; it only increases the total pollution load owing to the increase in the water quantity. However, its range is limited.

Step II: When the storage space of the deep tunnel is insufficient for sewage, the flood drainage pump units are opened gradually, one after the other, as the water depth increases until all the units start functioning; all these units discharge the sewage into Pearl River, which further enhances the drainage capacity of the deep tunnel. Although some of the flood drainage pump units start pumping floodwater partially into Pearl River, which affects the water quality of Pearl River, this pumping action plays a significant role in preventing pollution of the downstream water of DongHaoChong River, because the SISGD is opened well in advance. This step yields higher eco-efficiency.

\subsection{Reasonable Scenarios Analysis}

On the basis of the built urban rainstorm model of the DongHaoChong basin and the design rainfall graph described earlier, it is possible to obtain the maximum filling rate of the deep tunnel drainage system and the maximum head of the upstream SISGD in different regulation scenarios with different rainstorm design recurrence periods (Table 4). Return of a filled status by the deep tunnel drainage system in a particular regulation scenario and rainstorm design recurrence period will have adverse consequences on the deep tunnel drainage system [24]. Therefore, this regulation scenario is not recommended for responding to rainfall of such intensity. Additionally, the surface elevation of the upstream SISGD is about $9.5 \mathrm{~m}$. If the head of this sluice gate is close to or higher than $9.5 \mathrm{~m}$, it will lead to CSO pollution near the drainage pipe network. Therefore, the use of this regulation scenario when the basin experiences rainfall of such intensity is also not recommended. In other words, the appropriateness of using this regulation scenario to respond to rainfall of such intensity will be judged by considering whether the deep tunnel returns a filled status according to its filling rate and whether the head of the upstream SISGD is close to or higher than $9.5 \mathrm{~m}$. The simulation results for different rainstorm design recurrence periods are as presented below. 
Table 4. Maximum filling rate of the deep tunnel drainage system and maximum head of the upstream sewage interception sluice gate of DongHaoChong (SISGD) for rainstorms with different design recurrence periods.

\begin{tabular}{cccc}
\hline Rainfall of Intensity & Regulation Scenario & Maximum Filling Rate & Maximum Head \\
\hline \multirow{2}{*}{$p=0.2$} & Light rain & 1 & 8.93 \\
& Moderate rain & 0.98 & 8.12 \\
\hline \multirow{2}{*}{$p=0.5$} & Moderate rain & 1 & 9.78 \\
$p=1$ & Heavy rain & 0.66 & 8.63 \\
$p=2$ & Heavy rain & 0.76 & 8.94 \\
$p=5$ & Heavy rain & 0.82 & 9.16 \\
& Heavy rain & 0.88 & 9.37 \\
\hline
\end{tabular}

- $\quad$ Rainstorm design recurrence period $p=0.2$ year

When the basin experiences a rainfall of intensity $p=0.2$ year, regulation scenarios of light rain and moderate rain were used. When the regulation scenario of light rain was used, the SISGD was closed, as mentioned earlier. Meanwhile, the sewage drainage pump unit started pumping sewage partially to the WWTP. Table 4 shows that the system attained a filled status when the maximum filling rate was 1 . Therefore, the use of the light rain regulation scenario for responding to rainfall of $p=0.2$ year is not recommended. However, when the moderate rain regulation scenario was used, the deep tunnel drainage system was not filled up (the maximum filling rate was 0.98). In addition, the maximum head of the upstream SISGD did not exceed $9.5 \mathrm{~m}$ (Table 4). Therefore, the moderate rain regulation scenario is recommended in the event that the basin experiences rainfall of intensity $p=0.2$ year.

- Rainstorm design recurrence period $p=0.5$ year

According to the deep tunnel regulation scenario used for responding to rainfall of intensity $p=0.2$ year mentioned above, moderate rain and heavy rain regulation scenarios were used for the deep tunnel for $p=0.5$ year. Table 4 shows that for the moderate rain regulation scenario, the filled status was returned because of the increasing rainfall intensity, and the maximum head of the upstream SISGD increased rapidly to $9.78 \mathrm{~m}$. However, if the upstream SISGD is opened well in advance, the water quality at this gate does not meet the requirements. This will have more adverse impacts on the water quality downstream. Therefore, it is not advisable to use the moderate rain regulation scenario for rainfall of intensity $p=0.5$ year. Table 4 also shows that the filled status was not attained in the case of the heavy rain regulation scenario and that the maximum head was $8.63 \mathrm{~m}$; hence, CSO pollution was prevented by opening up of the flood drainage pump unit. Therefore, the use of the heavy rain regulation scenario is recommended in the event that the basin experiences rainfall of intensity $p=0.5$ year.

- Rainstorm design recurrence period $p=1$ year

For the return period of $p=1$ year for the deep tunnel, the heavy rain regulation scenario was used. Table 4 shows that the deep tunnel did not fill up in the heavy rain regulation scenario and that the maximum head was $8.94 \mathrm{~m}$. Therefore, the use of the heavy rain regulation scenario is recommended in the event that the basin experiences rainfall of intensity $p=1$ year.

- Rainstorm design recurrence period $p=2$ year

According to the regulation scenario corresponding to the case of $p=1$ year for the deep tunnel as mentioned above, the heavy rain regulation scenario was used even for $p=2$ year. Table 4 shows that in the heavy rain regulation scenario, the deep tunnel did not fill up during the storage process, 
because of the higher drainage capacity of the flood drainage pump unit. Meanwhile, its head changed stably, with the maximum head being $9.16 \mathrm{~m}$. In other words, the heavy rain regulation scenario is suitable for responding to rainfall of intensity $p=2$ year.

- $\quad$ Rainstorm design recurrence period $p=5$ year

The heavy rain regulation scenario was used for rainfall of intensity $p=5$ year. Table 4 shows that the deep tunnel drainage system did not fill up in the heavy rain regulation scenario. However, the basin rainfall intensity was greater than the inflow capacity of the drop shafts of the deep tunnel drainage system. Although the head of the upstream SISGD did not exceed $9.5 \mathrm{~m}$ (the maximum value was $9.37 \mathrm{~m}$ ), owing to the insufficient inflow capacity of the drop shafts, this head was close to the surface elevation near it. CSO pollution might have occurred if the SISGD was kept closed and not used to drain floodwater until the upstream water quality met the requirements. On the basis of the analysis results, it is recommended that the SISGD be opened well in advance to ensure the downstream water quality of DongHaoChong River from the viewpoints of securing the safety of upstream floodwater transportation and preventing flood. Therefore, it is proposed that the heavy rain regulation scenario be combined with the opening of the SISGD in advance in order to safeguard the basin in the event that the basin experiences rainfall of intensity $p=5$ year.

\subsection{Interception Effect Analysis}

When the highest regulation scenario (i.e., the heavy rain regulation scenario) is used for rainfall of intensity $p=5$ year, the deep tunnel drainage system cannot ensure both the upstream flood control safety and the downstream water quality, because of which the SISGD should be opened well in advance to prevent the upstream region from experiencing waterlogging. Even when the basin experiences rainfall of intensity $p=10$ year, the SISGD needs to be opened well in advance to transport the floodwater. Then, the deep tunnel drainage system is used mainly for controlling the flood disaster. Therefore, the pollutant interception effects for $p=5$ year and $p=10$ year are not analyzed in this study. The simulation results for rainstorms with different design recurrence periods in terms of the water quantity of the catchment outlet, total suspended solids (TSS), biochemical oxygen demand (BOD), chemical oxygen demand (COD), total phosphorus (TP), total nitrogen (TN), and ammonia-nitrogen (NH4-N) pollutant load are analyzed. The reduction in each index after analysis of the simulation results are listed in Table 5.

Table 5. Reduction in indexes after construction of DongHaoChong deep tunnel for rainstorms with different design recurrence periods.

\begin{tabular}{ccccccccc}
\hline $\begin{array}{c}\text { Rainfall of } \\
\text { Intensity }\end{array}$ & $\begin{array}{c}\text { Regulation } \\
\text { Scenario }\end{array}$ & $\begin{array}{c}\text { Water } \\
\text { Quantity/\% }\end{array}$ & TSS/\% & BOD/\% & COD/\% & TP/\% & TN/\% & NH4-N/\% \\
\hline$p=0.2$ & Moderate rain & 22.53 & 39.70 & 34.03 & 39.16 & 38.84 & 29.14 & 29.91 \\
$p=0.5$ & Heavy rain & 20.48 & 40.49 & 33.79 & 39.71 & 39.15 & 28.04 & 28.79 \\
$p=1$ & Heavy rain & 19.25 & 39.91 & 31.83 & 39.03 & 38.58 & 25.89 & 26.62 \\
$p=2$ & Heavy rain & 15.84 & 39.93 & 30.44 & 38.95 & 38.88 & 24.38 & 25.11 \\
\hline
\end{tabular}

\subsection{Comprehensive Analysis of Results}

The relevant curves obtained through simulation of the regulation scenarios for the deep tunnel drainage system for different rainstorm design recurrence periods, analysis of the interception effects of the corresponding regulation scenarios, and determination of the total water quantity and pollutant load before and after the construction of the deep tunnel are plotted in Figure 3. 

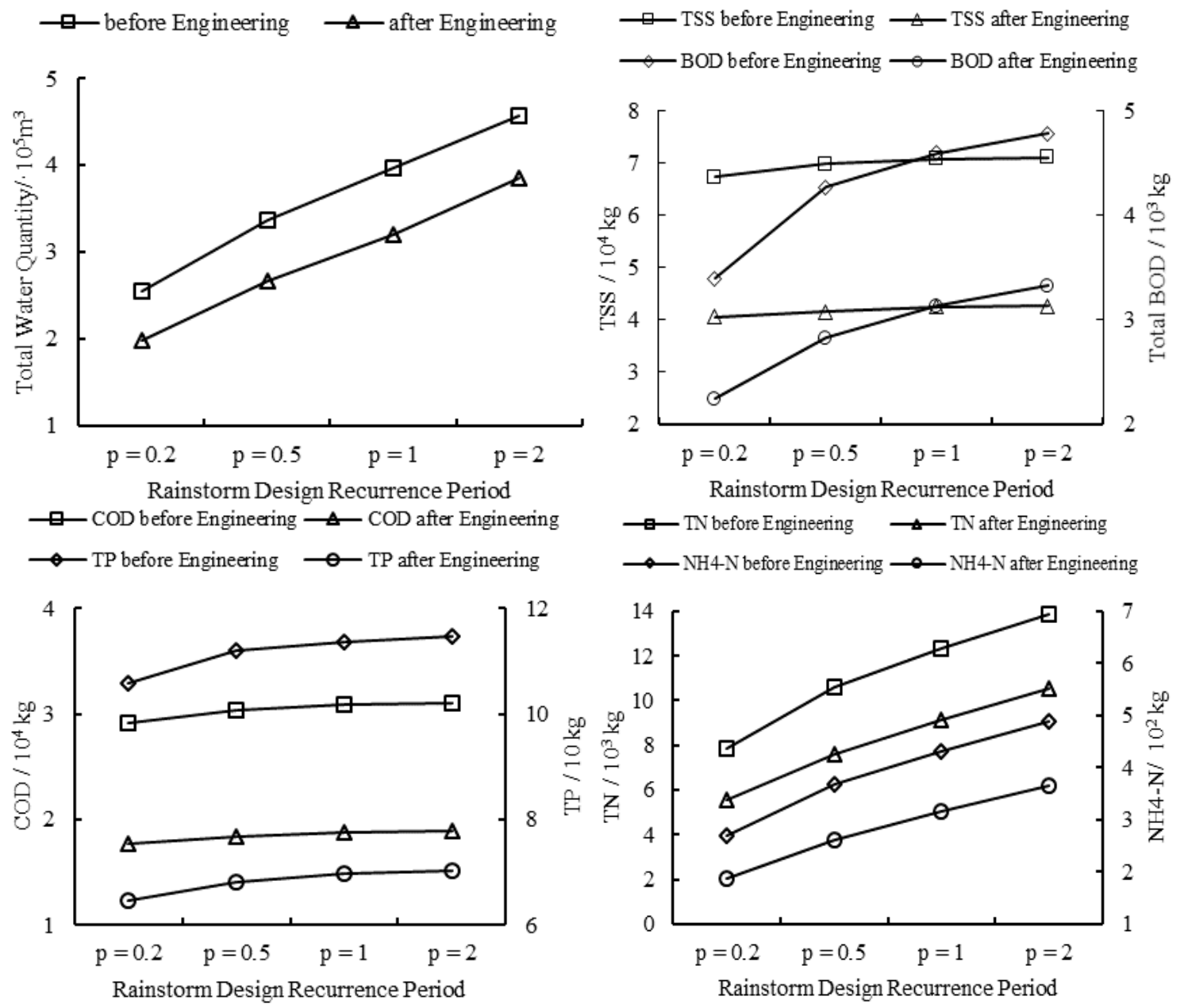

Figure 3. Comparisons of results for each index before and after construction of the deep tunnel for rainstorms with different design recurrence periods.

From the viewpoint of the total water quantity, with the aims of ensuring that the basin does not experience waterlogging during rainstorms and safeguarding the water quality in the region downstream of DongHaoChong River, the deep tunnel engineering will be successful in improving the flood control and drainage capacities of the basin to withstand rainfall with a design recurrence period of up to 2 years $1 \mathrm{~h}$ as opposed to 1 year $1 \mathrm{~h}$ earlier. The total water quantity at the outlet of the DongHaoChong downstream basin for the 2-year rainstorm design recurrence period after the construction of the deep tunnel will be lower than that for the 1-year rainstorm design recurrence period before its construction. The total water quantity at the outlet of the DongHaoChong downstream basin for the 1-year rainstorm design recurrence period after the construction of the deep tunnel will be lower than that for the 0.5-year rainstorm design recurrence period before its construction. Similarly, the total water quantity for the 0.5-year rainstorm design recurrence period after the construction of the deep tunnel will be equal to that for the 0.2-year rainstorm design recurrence period before its construction. That is, the DongHaoChong deep tunnel drainage system will mitigate the problems of downstream flood control and drainage pressure to a considerable extent. From the viewpoint of the pollutant load, although part of the sewage will be discharged into Pearl River through the flood drainage pump units in the heavy rain regulation scenario, the pollutant load flowing downstream of the DongHaoChong basin could be controlled well after the construction of the deep tunnel. 


\section{Conclusions}

Deep tunnels are increasingly being designed and constructed worldwide to solve problems related to CSO; the concept of deep tunnels is, nevertheless, a new and daring endeavor for China. The DongHaoChong deep tunnel is the first deep tunnel drainage system in China, and it is aimed at controlling CSO pollution and improving the river flood control and drainage capacities of the basin. Additionally, the application of the SWMM for the selection of reasonable scenarios and analysis of the effectiveness of the DongHaoChong deep tunnel is a novel approach that was adopted in this study. The results obtained from this study can be summarized as follows.

- When the basin experiences rainfall of intensity $p=0.2$ year, the deep tunnel drainage system should adopt the moderate rain regulation scenario. For rainfall of intensity $p=0.5$ year, the heavy rain regulation scenario should be employed. Finally, for rainfall events of intensities $p=0.5$ year, $p=1$ year, and $p=2$ year, the heavy rain regulation scenario should be employed. However, for rainfall events of intensities $p=5$ year and $p=10$ year, the deep tunnel drainage system should be used mainly for controlling the flood disaster. The SISGD should be opened well in advance to support the deep tunnel in controlling the flood disaster and preventing the occurrence of waterlogging in the basin.

- The DongHaoChong deep tunnel can reduce the initial rainwater source pollution load effectively. The interception effect for this load is different for rainstorms with different design recurrence periods and in different regulation scenarios. The TSS, BOD, COD, TP, TN, and NH4-N pollutant load for the different rainstorm scenarios was reduced by about $39.7 \%-40.61 \%, 29.78 \%-34.03 \%$, $38.98 \%-39.71 \%, 38.51 \%-39.51 \%, 22.64 \%-29.14 \%$, and $23.53 \%-29.91 \%$, respectively. The stored pollutant load was found to be extremely large before a rainstorm event. The deep tunnel drainage system will have a better interception effect in the case of the wash off of the initial rainwater.

- Because of the significant role of the deep tunnel drainage system in flood control and drainage, and from the viewpoint of safeguarding the role of the basin in preventing rainstorm waterlogging disasters and in protecting water quality in the downstream region of DongHaoChong River, the deep tunnel engineering was found to be successful in improving the flood control and drainage capacities of the basin to a rainstorm design recurrence period of up to 2-years.

Acknowledgments: This study was supported by the Special Funds for Public Welfare Projects of the Ministry of Water Resources of China (201301093); the Innovation Fund of Guangzhou City Water Science and Technology (GZSW-201401); and the State Key Lab of Subtropical Building Science, South China University of Technology (2014ZC09).

Author Contributions: Guoru Huang conceived this research, performed data collection. Haichun Wu, Licheng Li developed the models and carried out the model simulations. All the authors analyzed the results. Haichun Wu also wrote the manuscript.

Conflicts of Interest: The authors declare no conflict of interest.

\section{Abbreviations}

The following abbreviations are used in this manuscript:

$\begin{array}{ll}\text { DHC } & \text { DongHaoChong } \\ \text { CSO } & \text { combined sewer overflow } \\ \text { SWMM } & \text { Storm Water Management Model } \\ \text { SISGD } & \text { sewage interception sluice gate of DongHaoChong } \\ \text { WTP } & \text { water treatment plant } \\ \text { WWTP } & \text { wastewater treatment plant } \\ \text { FDSGLL } & \text { flood drainage sluice gate of Lu Lake } \\ \text { XHP-DSHLSG } & \text { Xinhepu-Dongshan Lake sluice gate } \\ \text { TSGD } & \text { tidal sluice gate of DongHaoChong } \\ \text { JWPS } & \text { Jiangwan pumping station }\end{array}$




$\begin{array}{ll}\text { DFRDS } & \text { Dongfeng Road drop shaft } \\ \text { ZS3RDS } & \text { Zhongshan 3 Road drop shaft } \\ \text { YDHDS } & \text { Yudaihao drop shaft } \\ \text { YJRDS } & \text { Yanjiang Road drop shaft } \\ \text { MGD } & \text { million gallons per day } \\ \text { MG } & \text { million gallons } \\ \text { XHPIP } & \text { Xinhepu interception pipes } \\ \text { DEM } & \text { digital elevation model } \\ \text { TSS } & \text { total suspended solids } \\ \text { BOD } & \text { biochemical oxygen demand } \\ \text { COD } & \text { chemical oxygen demand } \\ \text { TP } & \text { total phosphorus } \\ \text { TN } & \text { total nitrogen } \\ \text { NH4-N } & \text { ammonia-nitrogen }\end{array}$

\section{References}

1. Zhou, Q.; Ren, Y.; Xu, M.; Han, N.; Wang, H. Adaptation to urbanization impacts on drainage in the city of Hohhot, China. Water Sci. Technol. 2016, 73, 167-175. [CrossRef] [PubMed]

2. Liao, Z.L.; He, Y.; Huang, F.; Wang, S.; Li, H.Z. Analysis on lid for highly urbanized areas' waterlogging control: Demonstrated on the example of caohejing in Shanghai. Water Sci. Technol. 2013, 68, 2559-2567. [CrossRef] [PubMed]

3. Deng, W. Revitalization of Guangzhou Donghaochong River; The University of Hong Kong: Pokfulam, Hong Kong, 2010.

4. Ngo, T.T.; Yoo, G.D.; Lee, S.Y.; Kim, H.J. Optimization of upstream detention reservoir facilities for downstream flood mitigation in urban areas. Water 2016, 8, 290. [CrossRef]

5. Thomas, G.B.; Crawford, D. London tideway tunnels: Tackling london's victorian legacy of combined sewer overflows. Water Sci. Technol. 2011, 63, 80-87. [CrossRef] [PubMed]

6. Chanson, H. Hydraulics of rectangular dropshafts. J. Irrig. Drain. Eng. 2004, 130, 523-529. [CrossRef]

7. Carvalho, R.; Leandro, J. Hydraulic characteristics of a drop square manhole with a downstream control gate. J. Irrig. Drain. Eng. 2011, 138, 569-576. [CrossRef]

8. Granata, F.; de Marinis, G.; Gargano, R. Flow-improving elements in circular drop manholes. J. Hydraul. Res. 2014, 52, 347-355. [CrossRef]

9. Granata, F.; de Marinis, G.; Gargano, R.; Hager, W. Hydraulics of circular drop manholes. J. Irrig. Drain. Eng. 2010, 137, 102-111. [CrossRef]

10. Scalise, C.; Fitzpatrick, K. Chicago deep tunnel design and construction. In Structures Congress 2012; American Society of Civil Engineers: San Francisco, CA, USA, 2012; pp. 1485-1495.

11. Krebs, G.; Kokkonen, T.; Valtanen, M.; Koivusalo, H.; Setälä, H. A high resolution application of a stormwater management model (SWMM) using genetic parameter optimization. Urban Water J. 2013, 10, 394-410. [CrossRef]

12. Lee, S.-B.; Yoon, C.-G.; Jung, K.W.; Hwang, H.S. Comparative evaluation of runoff and water quality using hspf and swmm. Water Sci. Technol. 2010, 62, 1401-1409. [CrossRef] [PubMed]

13. Zhang, S.; Guo, Y. Analytical probabilistic model for evaluating the hydrologic performance of green roofs. J. Hydrol. Eng. 2012, 18, 19-28. [CrossRef]

14. Nanía, L.; León, A.; García, M. Hydrologic-hydraulic model for simulating dual drainage and flooding in urban areas: Application to a catchment in the metropolitan area of Chicago. J. Hydrol. Eng. 2014, 20, 04014071. [CrossRef]

15. Yu, H.; Huang, G.; Wu, C. Application of the stormwater management model to a piedmont city: A case study of Jinan city, China. Water Sci. Technol. 2014, 70, 858-864. [CrossRef] [PubMed]

16. Rossman, L.A. Storm Water Management Model User's Manual, Version 5.0; National Risk Management Research Laboratory, Office of Research and Development, US Environmental Protection Agency: Cincinnati, OH, USA, 2010.

17. James, W.; Rossman, L.A.; James, W.R.C. User's Guide to SWMM 5; Computational Hydraulics International (CHI): Guelph, ON, Canada, 2010.

18. Ho, C.; Su, J.; Tong, J. The usage of gis in stormwater management master plan. In Bridging the Gap; American Society of Civil Engineers: San Francisco, CA, USA, 2001; pp. 1-9. 
19. Bondar, C.; Hoy, M.; Schmidt, A. Gis-based support system for modeling Chicago's "deep tunnel” system. In World Environmental and Water Resource Congress 2006; American Society of Civil Engineers: San Francisco, CA, USA, 2006; pp. 1-10.

20. Liong, S.; Chan, W.; Lum, L. Knowledge-based system for swmm runoff component calibration. J. Water Resour. Plan. Manag. 1991, 117, 507-524. [CrossRef]

21. MOHURD; AQSIQ. Code for Design of Outdoor Wastewater Engineering (GB 50014-2006); Ministry of Housing and Urban-Rural Development, General Administration of Quality Supervision, Inspection and Quarantine of the People's Republic of China: Beijing, China, 2011. (In Chinese).

22. Barco, J.; Wong, K.; Stenstrom, M. Automatic calibration of the U.S. Epa swmm model for a large urban catchment. J. Hydraul. Eng. 2008, 134, 466-474. [CrossRef]

23. Granata, F.; Gargano, R.; de Marinis, G. Support vector regression for rainfall-runoff modeling in urban drainage: A comparison with the epa's storm water management model. Water 2016, 8, 1-13. [CrossRef]

24. Politano, M.; Odgaard, A.; Klecan, W. Case study: Numerical evaluation of hydraulic transients in a combined sewer overflow tunnel system. J. Hydraul. Eng. 2007, 133, 1103-1110. [CrossRef]

(C) 2016 by the authors; licensee MDPI, Basel, Switzerland. This article is an open access article distributed under the terms and conditions of the Creative Commons Attribution (CC-BY) license (http://creativecommons.org/licenses/by/4.0/). 